\title{
Are plot data effective for landscape prediction? A simulation study of tree species response to climate warming under varying environmental heterogeneity
}

\author{
Yu Liang $\cdot$ Hong S. He $\cdot$ Rencang Bu $\cdot$ Yuanman Hu • \\ Guofan Shao
}

Received: 24 September 2010 / Accepted: 28 February 2011 /Published online: 1 July 2011

(C) INRA and Springer Science+Business Media B.V. 2011

\begin{abstract}
- Introduction Extrapolating plot data to broader spatial scales depends largely on environmental heterogeneity.

- Objectives We studied this subject in the Changbai Mountains Natural Reserve in northeastern China by examining three scenarios of environmental heterogeneity. Scenarios 1, 2 and 3 represented local, class and zonal scale, and corresponded to the highest, intermediate and lowest level of environmental heterogeneity, respectively. Plot-level observation was represented by species establishment probability derived from an ecosystem process model that used plot observational data (e.g., weather, soil, vegetation, etc.) as input. Response variables at broader spatial scales, which were derived from a landscape model, included species total area and spatial pattern (measured by mean patch size) in the short, medium and long term. We examined whether these response variables differ statistically among the three scenarios.
\end{abstract}

\footnotetext{
Handling Editor: Erwin Dreyer

Y. Liang $\cdot$ H. S. He $\cdot$ R. Bu $\cdot$ Y. Hu $\cdot$ G. Shao

State Key Laboratory of Forest and Soil Ecology,

Institute of Applied Ecology, Chinese Academy of Sciences,

Shenyang 110016, China

Y. Liang

e-mail: liangysts@gmail.com

H. S. He $(\bowtie)$

School of Natural Resources, University of Missouri,

203m Anheuser-Busch Natural Resources Building,

Columbia, MO 65211-7270, USA

e-mail: HeH@missouri.edu

G. Shao

Department of Forestry and Natural Resources, Purdue University,

West Lafayette, IN 47907, USA
}

- Results Our results indicate that for species whose total area changes occur mainly within the same elevation zone in which the experimental plots reside, individual plots can capture the changes for the entire elevation zone. By contrast, for species that span many elevation zones under warming climate, plot-level observations are not reliable in predicting broader spatial scale change. Our results also suggest that species spatial patterns do not always coincide with those found for total area.

Keywords Climate warming - Extrapolation . Environmental heterogeneity. LANDIS · Changbai Mountains $\cdot$ Landscape prediction

\section{Introduction}

Forest ecosystems will change as a result of climate warming (Diaz et al. 2003; Chris et al. 2004), and most predictions of forest response to climate change are based on the combination of plot-level observations and model predictions (Zhao et al. 1998; Bugmann 2001; He et al. 2005). Experimental plots are used to monitor the relationship between forest ecosystems and climate change over the long term. Plot-level observations include measurements of physical parameters such as temperature and precipitation, and biological/ecological parameters such as tree growth rate, mortality, density and structure. The relationship between physical parameters and biological/ecological parameters are used to validate existing prediction models and develop new models to predict future forest conditions (Bugmann 1996; Deng et al. 2000; Bugmann 2001; He et al. 2002; Wang et al. 2009). In fact, the spatial extent to which the relationship is represented depends on the degree of spatial heterogeneity of the physical environment. 
Generally, a plot-level experiment is local and is conducted to represent the homogeneous environment in which the plot resides (Schmitz 2005). Thus, a low degree of spatial heterogeneity of physical environment across the landscape requires fewer plots than a high degree of spatial heterogeneity of physical environment (Peignéa et al. 2009).

Forest ecosystem research generally involves a limited number of experimental plots with fixed locations (e.g., long-term monitoring plots) in relatively homogeneous environments, and most existing long-term monitoring plots provide information only for a limited area of about 1-3 $\mathrm{km}^{2}$ (Running et al. 1999). Inexplicit assumptions are made regarding the heterogeneity of the physical environment if a limited number of plot-level observations is used to predict forest response to climate change for the entire study landscape.

Increasing attention has been paid to limited plot-level experiments in terms of whether they are reliable at predicting broader spatial scale change. In general, research results from local experiments may not scale readily to broad spatial extents. Species interactions at small spatial scales can be obscured by the effects of environmental heterogeneity at larger landscape scales (Steele and Forrester 2005). However, some researchers have also demonstrated that small-scale experiments can, with some ingenuity, be used to predict the magnitudes of broader scale responses (Melbourne and Chesson 2005; Schmitz 2005). Inouye (2005) used data collected at two nested spatial scales on the variances and covariances of distributions of species to parameterize a model for the regional population dynamics of these species that includes spatial heterogeneity at both spatial scales.

Despite many attempts, explicit assumptions still cannot be made about the heterogeneity of the physical environment and factors operating across various scales that drive observed spatial distributions (Resetarits 2005) because regional data may not be sufficient or may not have been derived reliably throughout the research at the local level (Huber et al. 2010). Attempts to extrapolate from plot-level experiments to species distributions across regions remain challenging; however, if spatial heterogeneity at different scales were quantified, available methods might allow integration of large-scale observational studies with small-scale experiments (Underwood et al. 2005).

In Changbai Natural Reserve of northeastern China, four long-term monitoring plots were established in the mid1980s to monitor the major forest ecosystems in the reserve. Due to limited resources and technical constraints, results from the limited monitoring plots have been used to represent a much larger area without evaluating the validity of spatial extrapolation (Cheng and Zhang 1991; Liu et al. 1998). Using results from plots with fixed numbers and locations to represent broader landscapes is not unique to our study area and is also used in other areas (Phillips et al. 1994; Liu et al. 1998; Picon et al. 2004; Chang et al. 2006).

Thus, the objective of this study was to evaluate the effects of extrapolating results from the current long-term monitoring plots to broader spatial scales on predicting total area and spatial pattern of tree species under climate warming. Specifically, we intend to investigate whether results from a local scale (land type unit) can be extrapolated to (1) an intermediate scale (land type units with the same aspect), and (2) zonal scale (land type units in the same elevation zone). In our study, plot-level observation was represented by species establishment probability derived from an ecosystem process model that uses the plot observational data (e.g., weather, soil, vegetation, etc.) as input. Response variables at broader spatial scales (species total area and spatial pattern) were derived from a landscape model. We examined whether these response variables differ statistically among the results derived from local, intermediate, and zonal scales. The findings of this study will have general relevance to other studies involving extrapolating limited plot-level results to broader spatial scales.

\section{Approaches and methods}

\subsection{Study sites}

Our study area (total area $4.1 \times 10^{5} \mathrm{ha}^{2}$ ) was the Changbai Mountain National Natural Reserve (CMNNR) and the $8 \mathrm{~km}$ surrounding area at $41^{\circ} 62^{\prime} \mathrm{N}$ to $42^{\circ} 49^{\prime} \mathrm{N}$ and $127^{\circ} 59^{\prime} \mathrm{E}$ to $128^{\circ} 38^{\prime} \mathrm{E}$ (Fig. 1). The CMNNR is a dormant volcano site in the eastern Jilin Province of northeast China. Established in 1960, the CMNNR protects one of the largest typical natural temperate forests in East Asia. The area has a temperate, continental climate, with long, cold winters and warm summers. Average annual precipitation and temperature are $1,012 \mathrm{~mm}$ and $-3.2^{\circ} \mathrm{C}$, respectively. The growing season is about 150 days. Changbai Mountain is the highest mountain in northeastern China and is the head of three large rivers (the Songhua, Yalu and Tumen) in

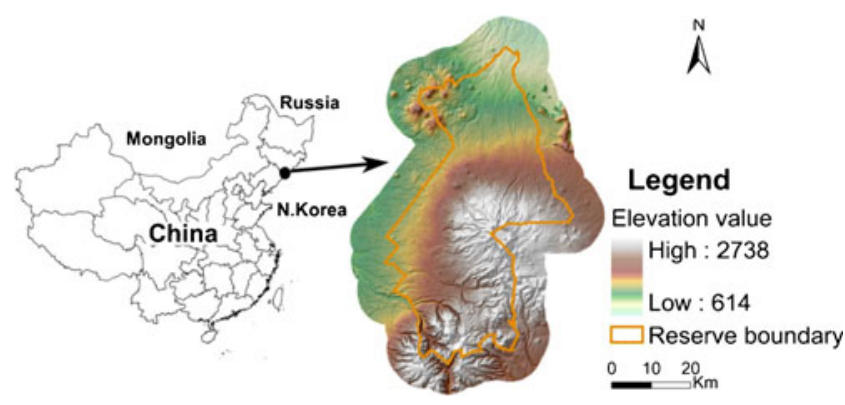

Fig. 1 Geographic site map of study area 
the northeastern provinces. Topographic features differ on the four slopes of the mountain, with the northern slope being relatively moderate (average slope $<3 \%$ ) and other slopes being relatively steep (average 10\%).

There are four vertical vegetation/elevation zones, from $740 \mathrm{~m}$ at the lowest elevation to $2,691 \mathrm{~m}$ at the summit of Changbai Mountains. From about 750 to $1,100 \mathrm{~m}$ is mixed Korean pine hardwood forest zone, including Korean pine (Pinus koraiensis), aspen (Poplus davidiana Dode), birch (Betula platyphylla Suk), basswood (Tilia amuresis Rupr), ash (Fraxinus mandshurica), oak (Quercus Mongolica), maple (Acer mono Maxim) and elm (Ulmus propingua). From 1,100 to $1,700 \mathrm{~m}$ is the evergreen coniferous forest zone dominated by spruce (Picea jezoensis) and fir [Abies nephrolepis (Trautv.) Maxim], with characteristics typical of boreal forests. From 1,700 to $2,000 \mathrm{~m}$ is the subalpine forest zone dominated by mountain birch (Betula ermanii Cham) and larch (Larix olgensis). Above 2,000 m includes tundra, bare rock and a volcanic lake (Shao et al. 1996). Hardwood forests extend $8 \mathrm{~km}$ outside the nature reserve (lower than $750 \mathrm{~m}$ elevation), where human activities have transformed the pine-hardwood forests into those composed mainly of hardwoods. Changbai Mountains also has azonal vegetation types and other land use types, such as larch forest, aspen-birch forest, alpine meadow, sparse forest, windthrow area, and abandoned forest, in addition to cutting sites and other human land use. Along with the zonal vegetation types, there are 20 land cover types, distributed largely together with elevation gradients.

The current four long-term monitoring plots (1 ha each) were established in mid-1980s to monitor the major forest ecosystems in Changbai Natural Reserve, with little attention paid to environmental heterogeneity. These plots reflect the current setting rather than a sampling design. At four long-term monitoring plots, tree species composition, crown closure, diameter at breast height $(\mathrm{DBH})$ of individual trees, species growth and mortality rate, daily weather, and some soil physical and chemical parameters were recorded.

\subsection{Assumptions of environmental heterogeneity}

Elevation and aspect are the most important factors causing spatial heterogeneity in the Changbai Mountains (Zhang et al. 2007), whereas slope has only moderate effects since most of the Changbai Mountains area has a slope $<10 \%$. Elevation is a physical factor governing broad scale forest distribution patterns and affecting land use, as reflected by distinct land cover types along elevation zones. Aspect is a physical factor governing fine scale species composition within a land cover type (or elevation zone).

A land cover type map of CMNNR and the $8 \mathrm{~km}$ surrounding area were derived from Landsat imagery (Shao et al. 1996), which classified the study area into 20 major land cover types. As described previously, zonal land cover types in CMNNR correspond to elevation zones. In this study, the aspect of CMNNR and the $8 \mathrm{~km}$ surrounding area were divided into five classes: north, south, west, east and flat. Land type units were derived by spatial overlay of land cover type map and aspect map, resulting in 95 types (some land cover types do not occur on the flat or other slopes, Table 1). Within each land type unit the physical environment was assumed homogeneous. Grouping land type units can represent assumptions of varying levels of environmental heterogeneity.

Three assumptions about environmental heterogeneity were made (Table 2). Assumption 1 (S1) assumes that the observed climate change at each experimental plot represents only the land type unit in which the plot resides and no climate change is observed in other land type units (Fig. 2c. S1). S1 represents the highest level of environmental heterogeneity as each patch is unique (local scale). Assumption 2 (S2) assumes the observed climate change at each experimental plot represents the land type units with the same aspect in the same elevation zone as the land type unit the plot resides, and no climate change is observed in other land type units. S2 represents an intermediate level of environmental heterogeneity as class or intermediate scale (Fig. 2c. S2). Assumption 3 (S3) assumes that the observed climate change represents land type units with all aspects in the same elevation zone as the land type unit in which the plot resides, and no climate change is observed in other land type units. S3 represents the lowest level environmental heterogeneity or zonal scale (Fig. 2c. S3). In addition to S1, $\mathrm{S} 2$, and S3, we also included Sc, a scenario of no climate warming and $\mathrm{Sw}$, a scenario in which every land type unit experiences climate warming (Table 2).

\subsection{Species response to climate warming under each assumption}

For each land type unit, current climate data was interpolated using ArcGIS based on climate data recorded at weather stations and monitoring plots. The result was convert into 24 grids, which represent current temperature distributions from January through December ( $\mathrm{He}$ et al. 1999, 2005). Warming climate data were generated from the second version of the Canadian Global Coupled Model (CGCM2) (Flato and Boer 2001). The average annual temperature predicted by CGCM2 increases by $4.6^{\circ} \mathrm{C}$ over the next 100 years (from the 1990s to the 2090s). To derive the climate warming data scenario, the monthly temperature differences were calculated between the warming and current climate (He et al. 2005). The predicted result of temperature change between 1990 and 2090 is linear, indicating that warming will occur gradually over the next 
Table 1 Cross referencing between land types derived from land cover types and aspects (only land types with total areas $\geq 1 \%$ of study area are presented). Elevation zones were identified to reflect major land cover types. See Fig. 2a for elevation zone and land cover type

\begin{tabular}{|c|c|c|c|}
\hline Land cover type & Aspect & Land type $(\%)$ & Elevation zone \\
\hline \multirow[t]{4}{*}{ Cutting site } & North & 5.7 & \multirow[t]{6}{*}{ Hardwood forest zone } \\
\hline & East & 2.9 & \\
\hline & South & 4.0 & \\
\hline & West & 5.2 & \\
\hline \multirow[t]{2}{*}{ Human landuse } & North & 1.0 & \\
\hline & West & 1.0 & \\
\hline \multirow[t]{3}{*}{ Korean pine hardwood forest I } & North & 3.4 & \multirow{8}{*}{$\begin{array}{l}\text { Korean pine hardwood } \\
\text { forest zone }\end{array}$} \\
\hline & East & 1.6 & \\
\hline & West & 2.3 & \\
\hline \multirow[t]{2}{*}{ Korean pine hardwood forest II } & North & 1.7 & \\
\hline & West & 1.4 & \\
\hline \multirow[t]{3}{*}{ Korean pine hardwood forest III } & North & 2.3 & \\
\hline & East & 1.6 & \\
\hline & West & 2.2 & \\
\hline \multirow[t]{4}{*}{ Spruce-fir forest I } & North & 1.6 & \multirow[t]{16}{*}{ Spruce-fir forest zone } \\
\hline & East & 1.0 & \\
\hline & South & 1.3 & \\
\hline & West & 1.6 & \\
\hline \multirow[t]{2}{*}{ Spruce-fir forest II } & North & 1.4 & \\
\hline & West & 1.4 & \\
\hline \multirow[t]{4}{*}{ Spruce-fir forest III } & North & 8.0 & \\
\hline & East & 3.1 & \\
\hline & South & 3.1 & \\
\hline & West & 6.1 & \\
\hline \multirow[t]{2}{*}{ Larch forest I } & North & 1.1 & \\
\hline & East & 1.6 & \\
\hline \multirow[t]{3}{*}{ Larch forest II } & North & 1.4 & \\
\hline & East & 2.4 & \\
\hline & South & 1.3 & \\
\hline Larch forest III & North & 1.0 & \\
\hline \multirow[t]{2}{*}{ Sub-alpine birch forest } & North & 1.0 & \multirow[t]{2}{*}{ Subalpine birch forest zone } \\
\hline & West & 1.0 & \\
\hline
\end{tabular}

100 years, as predicted by previous studies (Flato and Boer 2001), and that resultant warmed conditions persist for the simulation years after 2090 .

Within each land type unit, an ecosystem process model (LINKAGES) (Pastor and Post 1985; Post and Pastor 1996) was used to simulate the physiological response of each species to both current and warming climate as described previously (Hao et al. 2001; He et al. 2005). Equilibrium of individual species biomass was simulated using LINKAGES as a result of interactions of monthly climate, soil water and nutrients (e.g., soil water capacity, wilt point, total $\mathrm{N}$, and total $\mathrm{C}$ derived from soil survey data in CMNNR) (Hao et al.

Table 2 Five scenarios, numbers of land type unit represented by each scenario and percent area covered in each scenario in study area

\begin{tabular}{|c|c|c|c|}
\hline Scenario $^{\mathrm{a}}$ & Description & $\begin{array}{l}\text { Numbers of land } \\
\text { type unit represented }\end{array}$ & $\begin{array}{l}\text { Percent area } \\
\text { covered }\end{array}$ \\
\hline $\mathrm{Sc}$ & No observation station on all land cover types and all aspects (Fig. 2c. Sc) & 0 & 0 \\
\hline $\mathrm{S} 1$ & Observation station represents the land type unit it resides (Fig. 2c. S1) & 4 & 4 \\
\hline $\mathrm{S} 2$ & Observation station represents the land type unit with the same aspect (Fig. 2c. S2) & 8 & 12 \\
\hline S3 & Observation station represents the land type unit with all aspects (Fig. 2c. S3) & 20 & 34 \\
\hline Sw & Observation stations cover all land cover types and all aspects (Fig. 2c. Sw) & 95 & 100 \\
\hline
\end{tabular}

${ }^{\text {a }}$ Degree of spatial heterogeneity decreases from S1 to S3 

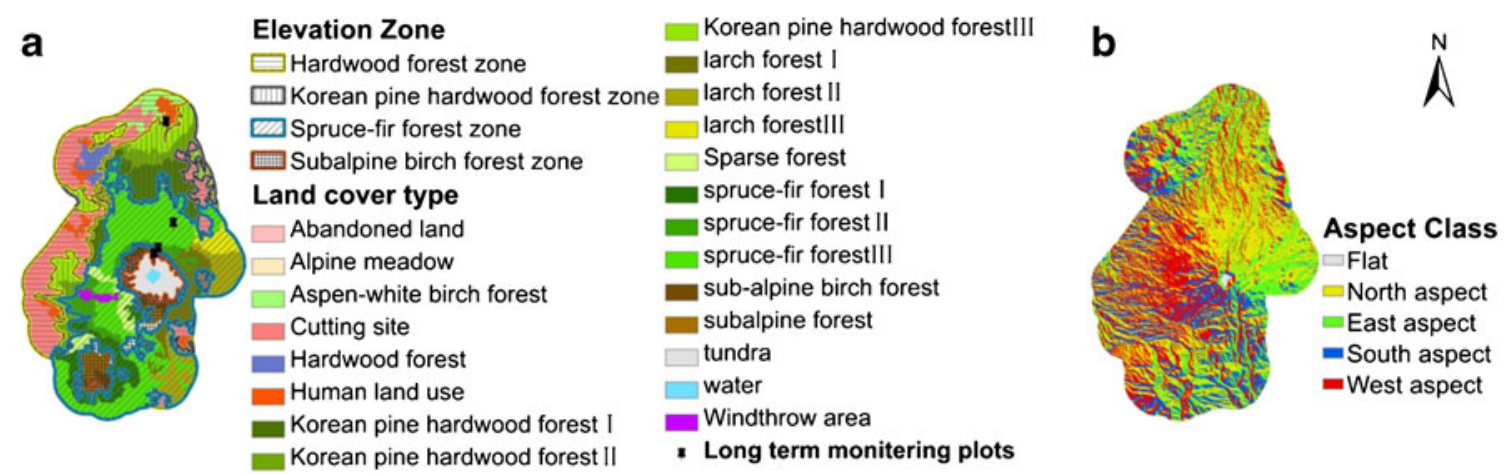

C
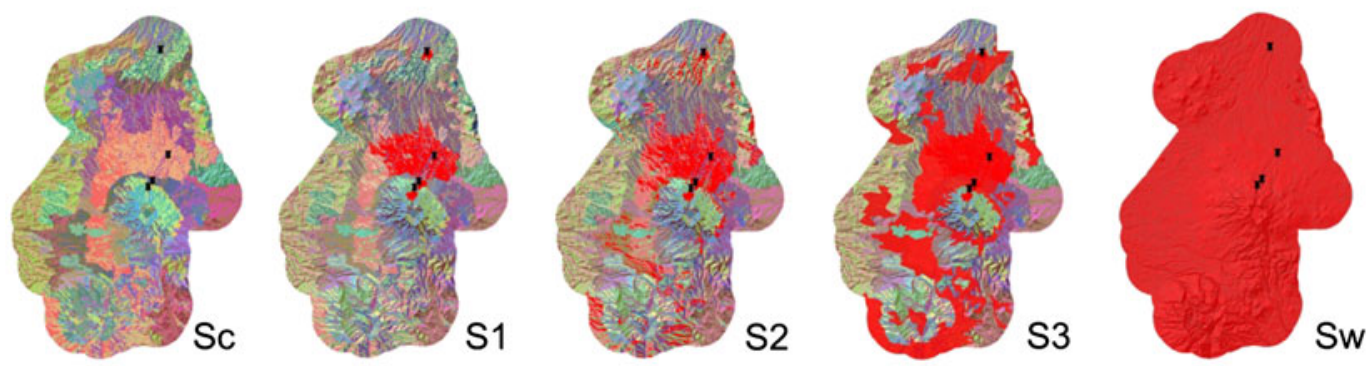

Legend

' Long term monitoring plots

-Observations under climate warming
Fig. 2 Parameterization of land type unit map and the design of five scenarios. a Major land cover types (20 types) and four elevation zones of Changbai Mountains, as derived from a classified remote sensing image (Shao et al. 1996). b Aspects of Changbai Mountains generated by digital elevation model (DEM) under ArcGIS. Land type

2001), and species biological traits (e.g., longevity, maturity, shade and drought tolerance, and seeding capability compiled based on previous studies in this area or derived from forest inventory data) (Wang et al. 1980; Yan and Zhao 1996; Hao et al. 2001). The biomass was converted to two sets of species establishment coefficient (SEC) for both the current and warming climate to quantify the environment suitability using an approach described by $\mathrm{He}$ et al. Values for SEC range from 0 to 1 , with high establishment coefficients having higher probabilities of establishment (Mladenoff and He 1999). The SEC for a given species was coincident with a homogeneous environment (in a land type unit) and might vary from one land type unit to another.

The LINKAGES model was coupled with a spatially explicit forest landscape model, LANDIS, which used SEC as a input parameter and simulated forest succession and landscape process (dispersal) for both current climate and warming climate (He et al. 2005) (Fig. 3). The effects of climate warming on each land cover type were derived from comparing the differences of LANDIS simulation results on species composition, spatial pattern and other traits for the two climate scenarios.

A key reason for employing the LANDIS modeling approach was that it has been parameterized and used to units are delineated based on existing land cover type map, elevation, and landform data under ArcGIS. These units were classified into homogeneous land type units based upon the similarity of the above variables. c Five scenarios (S1, S2, S3, Sc and Sw) and their observation areas under climate warming

predict the response of major forests to current and warming climate in Northern China, and uncertainty analysis on model parameterization and result variations has already been carried out (He et al. 1999, 2002; Xu et al. 2004, 2005).

Monitoring plots were used in two aspects in this study. First, data such as weather and soil from monitoring plots were used to parameterize the ecosystem process model, LINKAGES, which simulated the response of individual tree species to climate warming, and thus quantified the climate change effects on individual species at plot-scale. Second, the area that each plot represented or from which the climate change effect was extrapolated was determined based on the plot location under three assumptions of environmental heterogeneity.

The simulated scenarios were based on the assumption that SECs under warming climate represent only the corresponding land type unit in which the plot resides. In other words, the effects of climate change are observed only at the four monitoring plots, and the spatial extents of the observed warming effects vary under three respective assumptions (S1, S2, and S3). In a given scenario, we used the SEC from the current climate to reflect the fact that no climate warming effects were observed in areas where 
Fig. 3 Major components of the LANDIS model and the link with the LINKAGES model. In LANDIS, a landscape is divided into equal sized individual cells or sites. Each site $(i, j)$ on a certain land type unit, records a unique species list and age cohorts of species. Species establishment coefficients can be derived from LINKAGES, which synthesizes individual species responses to various climate and environmental conditions

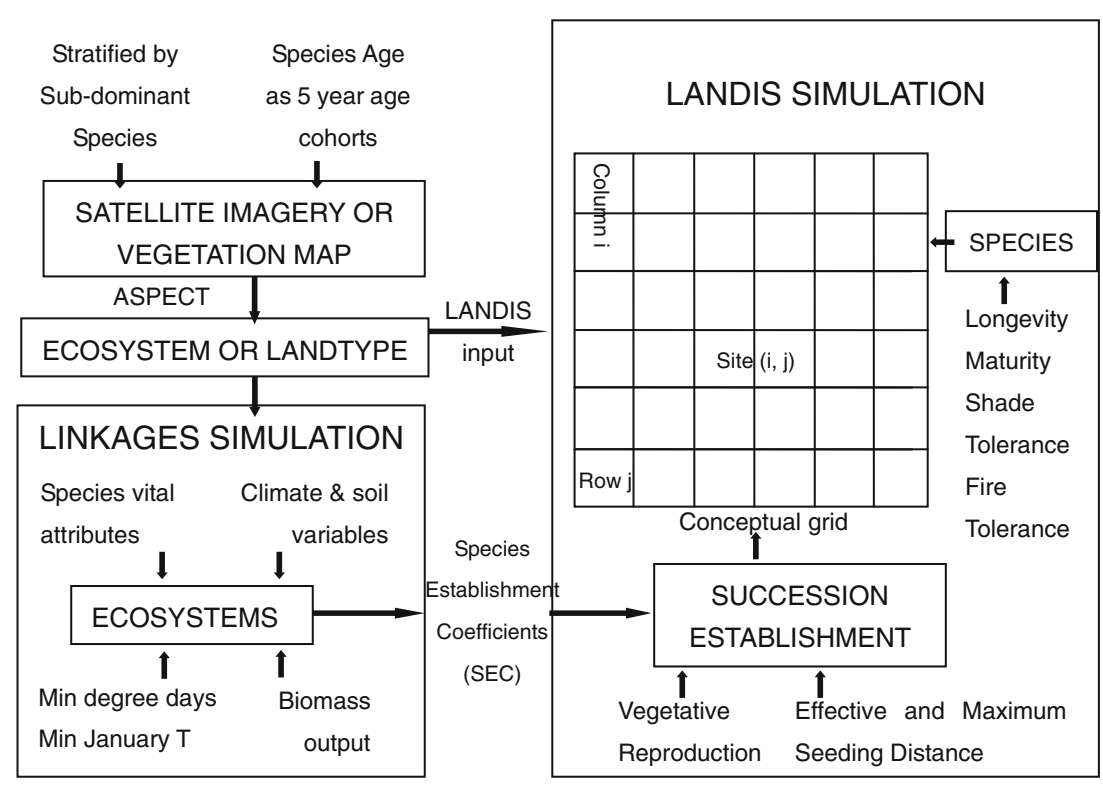

climate effects are not monitored, This treatment allows us to analyze circumstances under which the plot-level results can be extrapolated reliably to a broader spatial scale.

\subsection{Model simulation and data analysis}

To investigate whether species percent area and spatial pattern differ among three assumptions, we used LANDIS 6.0 (www.missouri.edu/ landis.htm) — an expanded version of LANDIS 4.0 (He et al. 2005) to simulate the 12 most common tree species (Korean pine, spruce, fir, mountain birch, birch, larch, oak, ash, maple, aspen, bass, and elm) from 1990 to 2190 in 5-year time steps. All spatial data were initialized at a resolution of $100 \times 100 \mathrm{~m}$, compatible with previous simulation studies, which yielded 960 rows and 647 columns (He et al. 2005). Disturbances such forest harvesting, fire, and wind were not simulated because our objective was to examine the natural successional trajectories of the main dominant species.

The uncertainties in the coupled models come from species establishment coefficient (SEC) derived by LINKAGES and the stochastic model components in LANDIS (e.g., seed dispersal and seedling establishment). The uncertainties of SEC were accounted for by 50 LINKAGES replicates used in the study. The work of Xu et al. $(2004,2005)$ showed that the uncertainty in LANDIS was low at the beginning of the simulation, increased with simulation year, and finally reached an equilibrium state where the uncertainties of input parameters had little effect on the simulation results at the landscape level (species percent area and their spatial patterns). This suggests that LANDIS can be used to predict the forest landscape change at broad spatial and temporal scales, even if exhaustive species physiological biochemical data for each cell is not available (Xu et al. 2004, 2005).
LANDIS 6.0 statistics was used to process LANDIS outputs (total area of the simulated species). The statistical results were summarized as percentage cover (the number of pixels in which a species occurs divided by the total number of pixels) by forest ecosystem. Simulation results were analyzed over short- (0-50 years), medium- (50100 years) and long-term (100-200 years) period. To quantify species spatial patterns, mean patch area (MPA) was calculated using the landscape statistical software, FRAGSTAT, and Arc/Info AML (Arc Macro Language) for assistance.

One-way ANOVA in SPSS 16.0 was used to analyze variance of species total areas and mean patch areas among five scenarios, each with five model replicates (five replication runs started with the same input parameters except random seed numbers in order to account for the effects of stochastic components such as seed dispersal and seedling establishment). Least significant difference (LSD) was used for multiple comparisons on the statistical significance of the coefficients. In one-way ANOVA, the factors were groups (five assumptions each with five model replicates), and the dependents were response variables (species total areas and mean patch areas of simulated species of five assumptions in the short-, medium- and long-term, respectively). Within-group (five replicates) variance is due entirely to stochastic components, and between-group variance is due to differences among scenarios. Response variables with significant differences between S1, S2 and S3 suggest that environmental heterogeneity affects prediction extrapolation from one scale to another and, therefore, plot-level observations are not reliable in predicting broader scale change. Response variables with no significant differences between S1, S2 and S3 suggest that the plot-level observations can scale up 
to class or zonal level. In addition, the results with significant differences between $\mathrm{Sc}$ and $\mathrm{Sw}$ in some species demonstrate that species was sensitive to climate warming and vice versa.

\section{Results}

3.1 Effects of levels of environmental heterogeneity on predicted total areas

Under the current climate scenario (Sc) and warming climate scenario $(\mathrm{Sw})$, a dramatic increase in total area of Korean pine and a gradual rise in total area of Mongolia oak were observed from the 1990s to 2190s. Moreover, total areas of Korean pine and oak under the Sw scenario increased less than those under the Sc scenario at the landscape level in the medium and long term (Fig. $4 \mathrm{a}_{\mathrm{II}}, \mathrm{a}_{\mathrm{III}}$, $b_{\text {II }}$ and $b_{\text {III }}$. For example, the mean total area of Korean pine in $\mathrm{Sw}$ was $1.3 \%$ less than in $\mathrm{Sc}$ for the long term. The results of ANOVA showed that total areas of Korean pine were significantly different between $\mathrm{S} 1$ and $\mathrm{S} 2, \mathrm{~S} 1$ and $\mathrm{S} 3$, and $\mathrm{S} 2$ and $\mathrm{S} 3$ in the short $\left(F=2.361 \times 10^{3} ; d f=24 ; P<\right.$ 0.05 ; Fig. $\left.4 \mathrm{a}_{\mathrm{I}}\right)$, and medium $\left(F=4.518 \times 10^{3} ; \mathrm{df}=24 ; P<\right.$ 0.01 ; Fig. $4 \mathrm{a}_{\text {III }}$ ) term. However, the total area of $\mathrm{S} 2$ in the long term was not significantly different from that of $\mathrm{S} 3$ $\left(F=3.579 \times 10^{3} ; d f=24 ; P>0.1 ;\right.$ Fig. $\left.4 \mathrm{a}_{\text {III }}\right)$. In contrast, total areas of oak between S1 and S2, S1 and S3, and S2 and $\mathrm{S} 3$ did not differ significantly in the short $(F=31.399$; $d f=24 ; P>0.05 ;$ Fig. $\left.4 \mathrm{~b}_{\mathrm{I}}\right)$, medium $(F=35.542 ; d f=24 ; P>$ 0.1 ; Fig. $\left.4 \mathrm{~b}_{\mathrm{II}}\right)$ and long $(F=31.755 ; d f=24 ; P>0.3$; Fig. $4 b_{\text {III }}$ ) term.

Spruce had a wider distribution than fir in our study area. The trajectory of percent cover for spruce suggested that its abundance increased significantly, from 11.6 to $26.8 \%$ under the current climate, and from 11.6 to $27.3 \%$ under the warming climate during the entire simulation period. ANOVA results showed that the total areas of spruce did not differ significantly between $\mathrm{S} 1$ and $\mathrm{S} 2$ in the short term $\left(F=10.060 ; d f=24 ; P>0.1\right.$; Fig. $\left.4 \mathrm{c}_{\mathrm{I}}\right)$ but differed significantly between $\mathrm{S} 1$ and $\mathrm{S} 2, \mathrm{~S} 1$ and $\mathrm{S} 3$, and $\mathrm{S} 2$ and $\mathrm{S} 3$ in the medium and long term $\left(P<0.05\right.$; Fig. $4 \mathrm{c}_{\mathrm{II}}$ and $\left.\mathrm{c}_{\mathrm{III}}\right)$. Under the Sc scenario, larch was projected to increase from $15.9 \%$ in 1990 to $29.4 \%$ in 2190 . Under the Sw scenario, however, larch increased more dramatically because of the favorable conditions and relatively lower competition from other species. The mean distributed area percent of larch in Sc, Sw, S1, S2 and S3 was 20.4, 20.5, 19.7, 20.4 and 20.5\%, respectively, in the short term (Fig. $\left.4 \mathrm{~d}_{\mathrm{I}}\right), 23.7,24.0,22.6$, 23.7 and $24.1 \%$, respectively, in the medium term (Fig. $4 \mathrm{~d}_{\mathrm{II}}$ ), and $26.1,26.6,24.6,26.1$ and $26.7 \%$, respectively, in the long term (Fig. $\left.4 \mathrm{~d}_{\mathrm{III}}\right)$. There were significant differences in species total areas of larch between $\mathrm{S} 1$ and $\mathrm{S} 2, \mathrm{~S} 1$ and $\mathrm{S} 3$, and $\mathrm{S} 2$ and $\mathrm{S} 3$ for the short, medium and long term $(P<0.01$; Fig. $4 d)$.

For some species (such as Korean pine, oak, fir, birch and larch), ANOVA results showed significant differences in total areas between the $\mathrm{Sc}$ scenario and $\mathrm{Sw}$ scenario during the entire simulated period $(P<0.01)$. However, for spruce, a significant difference occurred only in the long term $\left(F=130.613 ; d f=24 ; P<0.01 ;\right.$ Fig. $\left.4 \mathrm{c}_{\mathrm{III}}\right)$ and no significant differences between $\mathrm{Sc}$ and $\mathrm{Sw}$ were observed in the short $\left(F=10.060 ; d f=24 ; P>0.09\right.$; Fig. $\left.4 \mathrm{c}_{\mathrm{I}}\right)$ and medium $\left(F=32.529 ; d f=24 ; p>0.8\right.$; Fig. $\left.4 \mathrm{c}_{\text {II }}\right)$ term.

\subsection{Effects of levels of environmental heterogeneity} on species spatial pattern

Mean patch areas (MPAs) of Korean pine under the warming climate scenario (Sw) were 240.9 ha in the short term, 358.8 ha in the medium term and 388.3 ha in the long term (Fig. 5a,$a_{I I}$ and $a_{I I I}$ ). MPAs from the current climate scenario (Sc), S1, S2, S3, to Sw decreased sequentially during the entire simulation. Results of ANOVA indicated that the differences between $\mathrm{S} 1$ with $\mathrm{S} 2$ and between $\mathrm{S} 1$ with S3 were significant in the short $(F=396.270 ; d f=24$; $P<0.01$; Fig. $\left.5 \mathrm{a}_{\mathrm{I}}\right)$ and medium terms $(F=242.907 ; d f=24$; $P<0.05$; Fig. $\left.5 \mathrm{a}_{\mathrm{II}}\right)$, but no significant differences occurred between $\mathrm{S} 2$ and $\mathrm{S} 3$ in the short and medium term $(P>0.1)$. In contrast, in the long term there was no significant difference between $\mathrm{S} 1$ and $\mathrm{S} 2, \mathrm{~S} 1$ and $\mathrm{S} 3$, and $\mathrm{S} 2$ and $\mathrm{S} 3$ $\left(F=9.057 ; d f=24 ; P>0.1\right.$; Fig. $\left.5 \mathrm{a}_{\mathrm{III}}\right)$.

In the long term, oak MPAs (max. 117.6 ha in Sw and min. 119.8 ha in S3) were larger than those in the medium (max. 114.3 ha in Sw and min. 116.4 ha in S3) and short (max. 107.0 ha in Sw and min. 108.0 ha in S3) term (Fig. 5b). No significant differences between S1 and S2, S1 and $\mathrm{S} 3$, and $\mathrm{S} 2$ and $\mathrm{S} 3$ were found in the short, medium and long term $(P>0.05)$.

For spruce (Fig. $5 \mathrm{c}$ ), there were no significant differences between $\mathrm{S} 1$ and $\mathrm{S} 2, \mathrm{~S} 1$ and $\mathrm{S} 3$, and $\mathrm{S} 2$ and $\mathrm{S} 3$ in the short $(F=2.509 ; d f=24 ; P>0.06)$ and medium $(F=0.605 ; d f=24$; $P>0.4)$ term, and also no significant difference between $\mathrm{S} 1$ and $\mathrm{S} 2$ in the long term $(F=7.557 ; d f=24 ; P>0.8)$. However, significant differences were found between $\mathrm{S} 1$ with $\mathrm{S} 3$ and between $\mathrm{S} 2$ with $\mathrm{S} 3$ in the long term $(F=7.557 ; d f=24$; $P<0.01$; Fig. $5 \mathrm{c}_{\mathrm{III}}$ ). Larch MPAs in S1 (about 69 ha in the short term, 83 ha in the medium term and 89 ha in the long term) were significantly smaller than that in other scenarios during the entire simulation (Fig. $5 \mathrm{~d}_{\mathrm{I}}, \mathrm{d}_{\mathrm{II}}$ and $\mathrm{d}_{\mathrm{III}}$ ). Moreover, results of ANOVA showed that there were significant differences in MPAs of larch between S1 and S2, S1 and S3, and $\mathrm{S} 2$ and $\mathrm{S} 3$ for the short, medium and long terms $(P<0.01)$.

Results of ANOVA showed that MPAs of some simulated species (such as Korean pine, oak, fir, birch, mountain birch and larch) differed significantly between the Sc scenario 
Fig. 4 Effects of environmental heterogeneity levels on simulated species total areas in the short, medium and long term. a Korean pine, b oak, c spruce, $\mathbf{d}$ larch
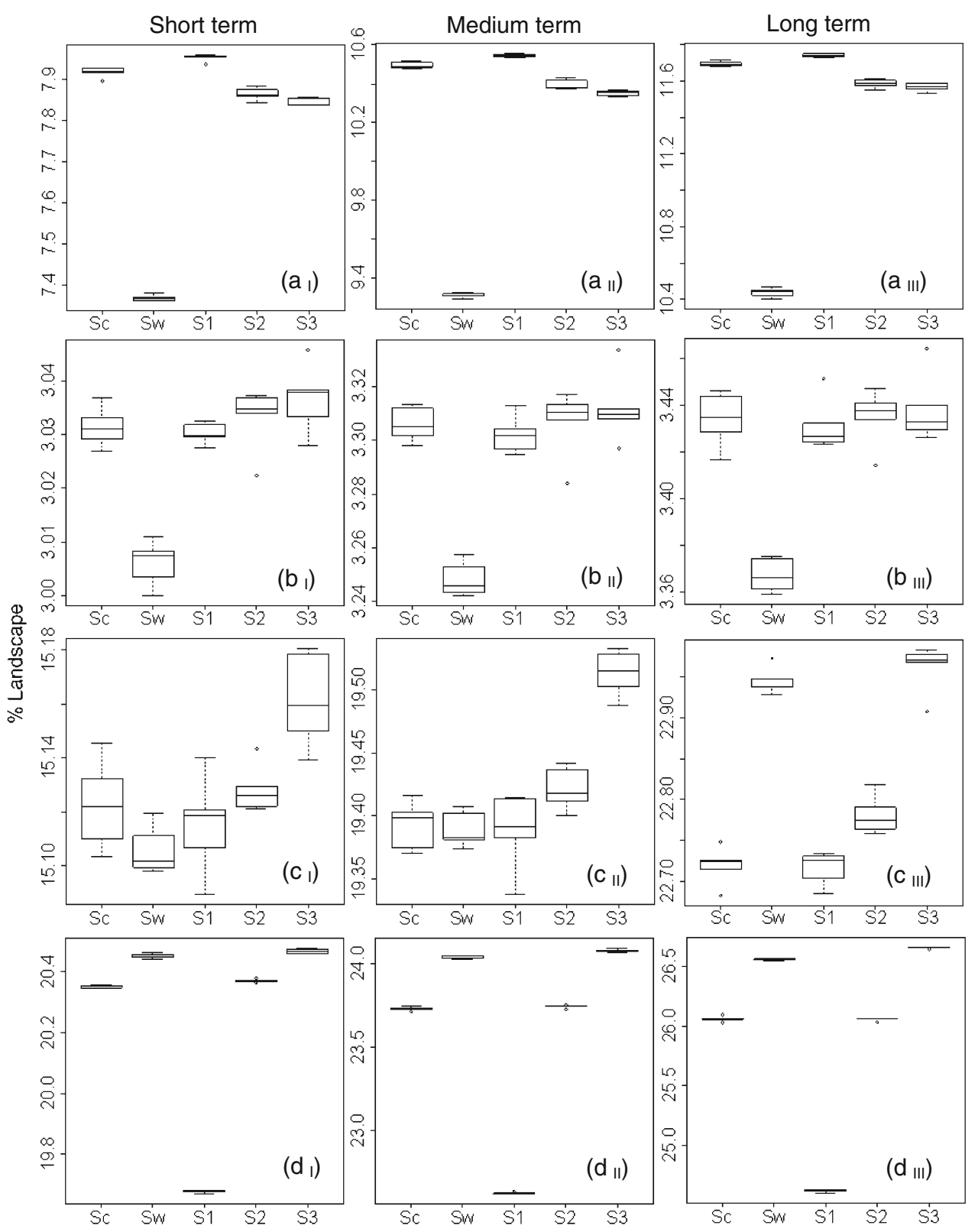

and Sw scenario during the entire simulated period $(P<0.01)$; however, for spruce, significant differences occurred only between the Sc scenario and $\mathrm{Sw}$ scenario in the short $\left(F=2.509 ; d f=24 ; P<0.05\right.$; Fig. $\left.5 \mathrm{c}_{\mathrm{I}}\right)$ and long $(F=7.557$; $d f=24 ; P<0.01$; Fig. $\left.5 \mathrm{c}_{\text {III }}\right)$ term, and there was no significant difference in the medium term $(F=0.605 ; d f=24$; $P>0.5$; Fig. $\left.5 \mathrm{c}_{\mathrm{II}}\right)$.

\section{Discussion}

Significant differences between the highest (S1) and medium level (S2) environmental heterogeneity suggest that results from individual plots cannot be extrapolated to land type units with the same as that in which aspect the plots reside. It also suggests that environmental heterogeneity limits plot-level results (local scale) from being scaled up to aspect class scale. The significant difference between the medium and low (S3) environmental heterogeneity scenario indicates that results of experimental plots derived for one aspect class cannot be extrapolated to all aspect classes. The significant difference between S1 and S3 suggests that plot-level observations are not reliable in predicting zonal scale change.

Our results showed that species total areas for some species did not differ significantly among all three levels of environmental heterogeneity in the short, medium and long term. For example, oak is a warming-adapted species (Zhao et al. 1998) that increases in total areas under the warming climate (demonstrated by the total area difference between 
Fig. 5 Effects of environmental heterogeneity levels on mean patch areas (MPAs) of simulated species in the short, medium and long terms. a Korean pine, b oak, c spruce, d larch
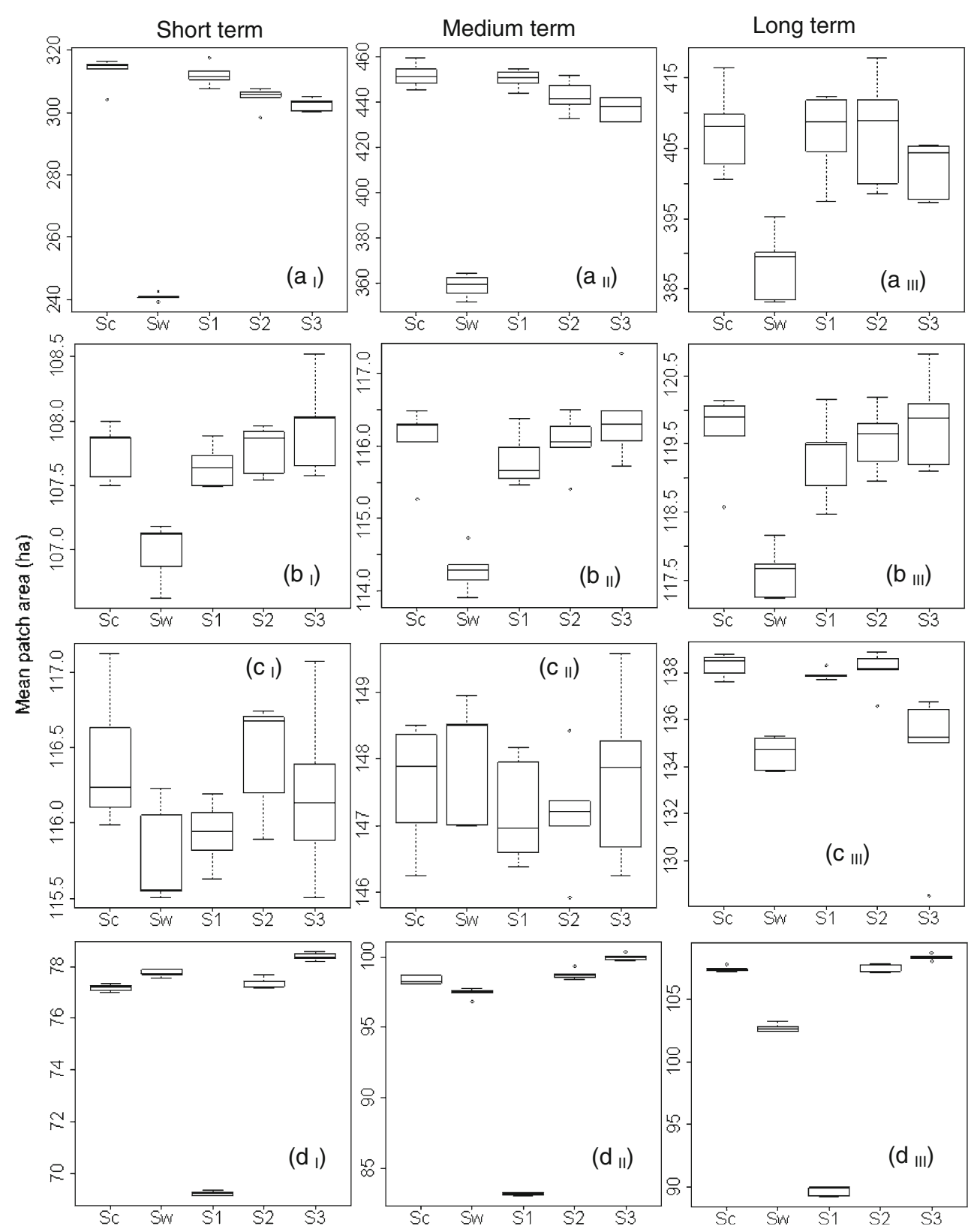

the current and warming scenarios) (Zhao et al. 1998). Oak coexists with Korean pine in the mixed Korean pine hardwood elevation zone (Wang et al. 1980). Under warming climate, oak cannot move to the higher elevation zone of spruce and fir because it has lower shade tolerance and cannot compete with existing spruce and fir (He et al. 2005). Thus, its increase in total area under climate warming was in the form of expanding from one aspect (south facing aspect) to other aspects within the same elevation zone. Consequently, the increase found at individual plots (S1) not only captured the changes in the entire land unit type with the same aspect the plot resides (S2) but also the changes in the same elevation zone as that in which the plot resides ( $\mathrm{S} 3$ ), resulting in no difference between $\mathrm{S} 1$ and $\mathrm{S} 2$, and $\mathrm{S} 2$ and $\mathrm{S} 3$.
Our results also show that total area for some species differed significantly among all three levels of environmental heterogeneity in the short, medium and long terms. Most of these species are climate sensitive species. For example, larch experienced a rise under warming climate, especially in the long term, which can be explained by the enlargement of the suitable habitat after warming (Leng et al. 2008). Larch is currently widespread in the Changbai Mountains (Yan and Zhao 1996; Zhao et al. 1998), adapts to diverse environmental conditions, and spans almost all elevation zones. Thus, individual plots (S1) cannot capture the changes in the entire land unit type with the same aspect as that in which the plot resides (S2) and also changes in the same elevation zone in which the plot resides (S3). 
The most common situation was that, for some species, under three levels of environmental heterogeneity species total area differed in some periods but not in other periods. For example, spruce is a climate-insensitive species and its total area does not change between current and warming climate (He et al. 2005). Its total area under three levels of environmental heterogeneity did not differ in the short term but differed in the medium and long term. This was because spruce migrate upward as a whole under warming climate. The difference of migration between warming and current climate was not obvious in the short term. However, in the medium and long term, spruce lost area against Korean pine at lower elevation but in higher elevation gained area against mountain birch, which is an early successional species (He et al. 2005). Such a shift in elevation zone makes plot-level observations of spruce reliable in predicting future forest landscape for the short term but unreliable for the medium and long term. Korean pine is a warmingadapted species. Its total area increased dramatically in the short and medium term and maintained a stable range in the long term under both current and warming climate (He et al. 2005). Korean pine total area differed in the short and medium term under three levels of environmental heterogeneity but did not differ in the long term. Historical harvest of Korean pine led to low total area of this regionally dominant tree species at the beginning of our model simulation. Since harvest was not simulated (not allowed), Korean pine shown a strong recovery in the short and medium term. Such a recovery cannot be reflected by species establishment coefficients derived from the individual land type units under warming climate, resulting in a significant difference when extrapolating results from individual land unit (S1) to land units with the same aspect (S2), and between land units of one aspect (S2) and land units of all aspects (S3). Although under warming climate, Korean pine can compete with spruce and fir at their lower elevation zone, the limited Korean pine seeds and dispersal due to historical harvest have limited large scale landscape transition from spruce-fir to mixed Korean pine forest. Thus, the increase in total area of Korean pine under climate warming in the long term was mostly within its current elevation zone. Consequently, results from experimental plots derived for one aspect class can be extrapolated to all aspect classes in the long term.

The results suggested that differences found for species spatial patterns under three levels of environmental heterogeneity did not always coincide with those found for total area. For example, percent area for Korean pine was significantly different under three levels of environmental heterogeneity in the short and medium term, and did not differ between land units of one aspect (S2) and land units of all aspects (S3) in the long term. However, spatial pattern did not differ between land units of one aspect (S2) and land units of all aspects (S3) in the short and medium term and also did not differ under three levels of environmental heterogeneity long term, suggesting that Korean pine distribution developed a stable pattern within its elevation zone under warming climate.

Although the results of this study might have differed if different monitoring plots were used, they provide new insights into extrapolating plot-level studies to broader spatial scales. This study provides a basis for further study of sampling questions such as sensitivity of species area estimation to plot number and location in predicting forest landscape change under climate warming, and the relationship between sampling design and error estimate.

\section{Conclusions}

We investigated whether data from plot-level observations are reliable when extrapolating to large spatial extents with environments heterogeneity under warming climate. Our results indicate that for some species (e.g., oak and birch), warming-induced changes occur mainly within the same elevation zone as the monitoring plots, and therefore results from these plots can capture the changes for the entire elevation zone. By contrast, for other species (e.g., larch or spruce) that span many elevation zones or migrate from one elevation zone to another under warming climate, plot-level observations are not reliable in predicting changes for the elevation zone. The most complicated situation is that for some species plot-level observations are reliable in predicting species total area for some periods but not reliable for other periods. Such a situation can be due to various factors, including limited dispersal capability and past human harvest, that affected seed sources and subsequently delay recovery. Our results also suggest that species spatial patterns do not always coincide with those found for total area; whether plot-level observations can capture species spatial pattern at larger scales depends on whether the species distribution can develop a stable pattern under warming climate.

Acknowledgments We thank anonymous reviewers for providing critical comments that greatly improved the manuscript. We thank Janice Faaborg for improving the English of this manuscript.

Funding This research is funded by the Chinese Academy of Sciences project KZCX2-YW-T06 and KZCX2-YW-444.

Author contributions Y.L. participated in experimental design, conducted model simulation and data analysis, and led in manuscript writing, H.S.H. is the principal investigator, participated in project design and manuscript writing, R.B. participated in data analysis and model simulation, Y.H. participated in experimental design, and G.S. participated in project design. 


\section{References}

Bugmann H (1996) A simplified forest model to study species composition along climate gradients. Ecology 77:2055-2074

Bugmann H (2001) A review of forest gap models. Clim Chang 51:259-305

Chang CR, Lee PF, Bai ML, Lin TT (2006) Identifying the scale thresholds for field-data extrapolation via spatial analysis of landscape gradients. Ecosystems 9:200-214

Cheng BR, Zhang J (1991) Preliminary study on chemistry of leacheate and soils under coniferous forest on northern slope of Changbai Mountains. Acta Pedol Sin 28:372-380

Chris DT, Alison C, Rhys EG, Michel B et al (2004) Extinction risk from climate change. Nature 427:145-148

Deng H, Wu Z, Zhou D (2000) Response of broadleaved Pinus koraiensis forests in Xiaoxinganling Mt. to global climate change -a dynamic modeling. Chin J Appl Ecol 11:43-46

Diaz HF, Grosjean M, Graumlich L (2003) Climate variability and change in high elevation regions: past, present and future. Clim Chang 59:1-4

Flato GM, Boer GJ (2001) Warming asymmetry in climate change simulations. Geophys Res Lett 28:195-198

Hao ZQ, Dai LM, He HS, Mladenoff DJ, Shao GF (2001) Potential response of major tree species to climate warming in Chingbai Mountain. Chin J Appl Ecol 12:653-658

He HS, Mladenoff DJ, Crow TR (1999) Linking an ecosystem model and a landscape model to study forest species response to climate warming. Ecol Model 112:213-233

He HS, Hao ZQ, David RL, Dai LM, Hu YM, Chang Y (2002) A simulation study of landscape scale forest succession in northeastern China. Ecol Model 156:153-166

He HS, Hao ZQ, Mladenoff DJ, Shao GF, Hu YM, Chang Y (2005) Simulating forest ecosystem response to climate warming incorporating spatial effects in north-eastern China. J Biogeogr 32:2043-2056

Huber PR, Greco SE, Thorne JH (2010) Spatial scale effects on conservation network design: trade-offs and omissions in regional versus local scale planning. Landsc Ecol 25:683-695

Inouye BD (2005) Scaling up from local competition to regional coexistence across two scales of spatial heterogeneity: insect larvae in the fruits of Apeiba membranacea. Oecologia 145:188196

Leng WF, He HS, Liu ZH (2008) Response of larch species to climate changes. J Plant Ecol 1:203-205

Liu QJ, Kondoh A, Takeuchi N (1998) The forest vegetation and its differentiation under disturbance in a temperate mountain, China. J For Res 3:111-117

Melbourne BA, Chesson P (2005) Scaling up population dynamics: integrating theory and data. Oecologia 145:179-187

Mladenoff DJ, He HS (1999) Design and behaviour of LANDIS, an object-oriented model of forest landscape disturbance and succession. In: Mladenoff DJ, Baker WL (eds) Advances in spatial modeling of forest landscape change: approaches and applications. Cambridge University Press, Cambridge, pp 125-162
Pastor J, Post WM (1985) Development of a linked forest productivitysoil process model. Oak Ridge National Laboratory, Oak Ridge, TN

Peignéa J, Vian JF, Mario C, Bottollier B, Rémi C (2009) Soil sampling based on field spatial variability of soil microbial indicators. Eur J Soil Biol 45:488-495

Phillips OL, Hall P, Gentry AH, Sawyer SA, Vasquez R (1994) Dynamics and species richness of tropical rain forests. Proc Natl Acad Sci USA 91:2805-2809

Picon MC, Henry CB, Guibal F, Roux M (2004) Dendrometry and morphometry of Pinus pinea L. in Lower Provence (France): adaptability and variability of provenances. For Ecol Manag 194:319-333

Post WM, Pastor J (1996) Linkages - an individual-based forest ecosystem model. Clim Chang 34:253-261

Resetarits WJ (2005) Habitat selection behaviour links local and regional scales in aquatic systems. Ecol Lett 8:480-486

Running SW, Baldocchi DD, Turner D, Gower ST, Bakwin P, Hibbard K (1999) A global terrestrial monitoring network integrating tower fluxes, flask sampling, ecosystem modeling and EOS satellite data. Remote Sens Environ 70:108-127

Schmitz OJ (2005) Scaling from plot experiments to landscapes: studying grasshoppers to inform forest ecosystem management. Oecologia 145:225-234

Shao GF, Zhao G, Shugart HH, Wang S, Schaller J (1996) Forest cover types derived from Landsat Thematic Mapper imagery for the Changbai Mountain area of China. Can J For Res 26:206-216

Steele MA, Forrester GE (2005) Small-scale field experiments accurately scale up to predict density dependence in reef fish populations at large scales. Proc Natl Acad Sci USA 102:13513-13516

Underwood N, Hamback P, Inouye BD (2005) Large-scale questions and small-scale data: empirical and theoretical methods for scaling up in ecology. Oecologia 145:177-178

Wang Z, Xu Z, Tan Z, Dai H, Li X (1980) The main forest types and their features of community structure in northern slope of Changbai Mountain. For Ecol Res 1:25-42

Wang YQ, Zhou Y, Yang J, He HS, Zhu Z, Ohlen D (2009) Simulation of short-term post-fire vegetation recovery by integration of LANDFIRE data products, DNBR data and LANDIS modeling. Ann GIS 15:47-59

Xu CG, He HS, Hu YM, Chang Y, Larsen DR, Li XZ, Bu RC (2004) Assessing the effect of cell-level uncertainty on a forest landscape model simulation in northeastern China. Ecol Model 180:57-72

Xu CG, He HS, Hu YM, Chang Y, Li XZ, Bu RC (2005) Latin hypercube sampling and geostatistical modeling of spatial uncertainty in a spatially explicit forest landscape model simulation. Ecol Model 185:255-269

Yan XD, Zhao S (1996) Simulating the response of Changbai Mt. forests to potential climate change. J Environ Sci 8:354-366

Zhang N, Yu ZL, Yu GR, Wu JG (2007) Scaling up ecosystem productivity from patch to landscape: a case study of Changbai Mountain Nature Reserve, China. Landsc Ecol 22:303-315

Zhao SD, Yan XD, Yang SH, Tao DL, Dai LM (1998) Simulating responses of northeastern China forests to potential climate change. J For Res 9:166-172 